\title{
REPRESENTAÇÕES SOCIAIS DE ESTUDANTES UNIVERSITÁRIOS SOBRE COTAS NA UNIVERSIDADE
}

\author{
Paula Bacellar e Silva \\ Patrícia da Silva $\star \star$
}

\begin{abstract}
RESUMO
Foram analisadas as representações sociais de estudantes universitários sobre o sistema de reserva de vagas com base em critérios raciais e sociais nas universidades. Participaram sete estudantes, de ambos os sexos, com idades entre 19 e 49 anos, sendo dois beneficiados pelas cotas. Utilizou-se a técnica de grupo focal, tendo como pergunta inicial "O que vocês pensam sobre o sistema de cotas na universidade?", e um questionário para dados socioeconômicos. Os dados foram analisados através análise de conteúdo temática, não quantitativa. Os resultados indicam um discurso contraditório e ambivalente (contrário, favorável e em alguns momentos ambivalentes), por outro lado, no que se refere ao convívio com estudantes cotistas houve uma tendência em concebê-los de forma estereotipada, portanto, homogênea. Espera-se que este estudo contribua para melhor compreensão do fenômeno e possibilite novas pesquisas e reflexões sobre as representações sociais da política de cotas.
\end{abstract}

Palavras-chave: representações sociais; cotas universitárias; cotistas.

\section{SOCIAL REPRESENTATION OF UNIVERSITY STUDENTS ON THE UNIVERSITY QUOTA SYSTEM}

\begin{abstract}
The study had as objective to know the social representations of university students on the system of reserving space based on racial and social criteria in the university. Seven students participated from diverse fields of study at UFBA, of both sexes, with age group ranging from 19 to 49 years of age, where two of them benefited from quotas. The focus group technique was used having the initial question "What do you think about the university quota system?", and a questionnaire for socioeconomic data. The data was transcribed and a non-quantitative, thematic

\footnotetext{
^ Psicóloga. Doutoranda do Programa de pós-graduação em Psicologia Social - Universidade Federal da Bahia. Endereço: Universidade Federal da Bahia - Instituto de Psicologia. Rua Aristidis Novis, Estrada de São Lazáro, 197. Salvador, Ba. CEP 40210-730

E-mail: polinhabacellar@gmail.com Bahia

E-mail: dasilvapaty@yahoo.com.br
}

$\star \star$ Doutoranda do Programa de pós-graduação em Psicologia Social - Universidade Federal da
\end{abstract}


content analysis was made. The results indicate a contradictory and ambivalent discourse (contrary, favorable and at times ambivalent), on the other hand, as for living together with quota students there was a tendency to perceive them as stereotyped, and therefore, homogenous. Hopefully, this study will contribute toward a better understanding of the phenomenon and make possible new studies and reflections about the social representations of quota politics.

Keywords: Social representations; university quotas; quota.

Esta investigação teve como objetivo conhecer e analisar as representações sociais de estudantes universitários sobre a política de reserva de vagas raciais e sociais adotada na Universidade Federal da Bahia. Para alcançar este objetivo, conduziu-se uma breve revisão conceitual e histórica sobre políticas de ação afirmativa, contextualizando a discussão sobre cotas universitárias. Em seguida, foi apresentada a teoria das representações sociais, justificando as escolhas teóricas e metodológicas feitas aqui.

\section{BREVE hiSTÓRICO SOBRE POLÍTICAS DE AÇÃo AFIRMATIVA}

Ações afirmativas consistem em políticas públicas ou privadas, que possuem o objetivo de neutralizar os efeitos da discriminação racial, gênero, idade, origem nacional e aparência física (GOMES, 2003). Desta maneira, os esforços de uma organização ou governo, para que as minorias tenham as mesmas chances de serem contratados, mantidos, promovidos ou educados constituem uma política de ação afirmativa, seja no trabalho ou na educação (CROSBY; CORDOVA, 1996).

As ações afirmativas são definidas como "ações públicas ou privadas (ou programas) que provêm ou buscam prover oportunidades ou outros benefícios para pessoas, com base, entre outras coisas, em sua pertença a um ou mais grupos específicos" (JONES, 1993, p. 345, tradução nossa). Tais programas têm como princípio fundamental o sentido de equidade social ou de administração da justiça em situações particulares e não universais. Objetivando, portanto garantir a ascensão de minorias étnicas, raciais e sexuais a algum bem ou status social.

Apesar do debate sobre a ação afirmativa na sociedade brasileira ser bastante atual e acalorado graças à implementação do sistema de reserva de vagas nas universidades públicas brasileiras, a ação afirmativa, enquanto mecanismo de integração social, não é recente. Diversos países já passaram por essa experiência, ainda que sob uma multiplicidade de rótulos, como "discriminação positiva" ou "ação positiva", como é conhecida na Europa, ou ainda "política de cotas", "ação compensatória" e "reserva de vagas" (GOMES; SILVA, 2003; MOEHLECKE, 2002).

As políticas de ações afirmativas, segundo Brandão (2005), não se limitam apenas à proibição da discriminação, mas se propõem a combatê-la e a promover a reparação de injustiças perpetradas contra grupos minoritários, lidando proativamente com o problema da discriminação e a subrrepresentação dessas 
nas organizações (HING; BOBOCEL; ZANNA, 2002). Em outras palavras, a ação afirmativa visa à redução da desigualdade, ao dar condições às minorias no acesso à educação, emprego e promoções, levando em consideração que esta igualdade não ocorreria sem a existência de tais medidas devido à discriminação.

O país pioneiro na adoção do sistema de cotas raciais foi a Índia, na década de 1930, a fim de favorecer o acesso dos Dalits, a casta mais baixa e discriminada da Índia, ao ensino superior. Naquele país, as cotas estão em vigor desde a Constituição de 1949 hoje, sendo obrigatórias no serviço público, na educação e em todos os órgãos estatais. De acordo com Carvalho (2005a), a Índia é um exemplo positivo da utilização do sistema de cotas, tendo em vista que, em 1950, apenas $1 \%$ dos Dalits tinha curso superior, enquanto em 2005 esse percentual aumentou para $12 \%$.

As ações afirmativas são empregadas, até os dias atuais, em muitos países da Europa Ocidental, Malásia, Sri Lanka, Nigéria, África do Sul, Austrália, Canadá, Cuba, Argentina, Brasil e Estados Unidos, dentre outros (MOEHLECKE, 2002; SOWELL, 2004).

Nesses diferentes contextos, as ações afirmativas, segundo Moehlecke (2002), assumiram formas diversas, que vão desde ações voluntárias até as de caráter obrigatório, reguladas pelo governo ou pela iniciativa privada, orientadas por leis e decisões jurídicas ou por agências de fomento e regulação. Diversas minorias foram beneficiadas, sendo as principais áreas contempladas o mercado de trabalho (contratação, qualificação e promoção de funcionários); o sistema educacional (especialmente o ensino superior); e a representação política.

No Brasil, de acordo com Brandão (2005), as primeiras medidas de ações afirmativas foram voltadas para a promoção da entrada de deficientes físicos no mercado de trabalho. Desde a constituição de 1988, os deficientes físicos são beneficiados por uma reserva de vagas de emprego em empresas e no serviço público. Medida semelhante foi adotada em relação à publicidade e à propaganda, no ano de 1996, no Distrito Federal, Espírito Santo, Minas Gerais e Bahia, quando, através de leis municipais, foram determinadas cotas, regulamentando a porcentagem étnica na contratação de modelos, a ser condizente com a diversidade étnica de cada estado.

A prática mais conhecida de ações afirmativas é o sistema de cotas, que consiste em "estabelecer um determinado número ou percentual a ser ocupado, em área específica, por grupo(s) definido(s), o que pode ocorrer de maneira proporcional ou não, e de forma mais ou menos flexível" (MOEHLECKE, 2002, p. 117).

Atualmente, de acordo com um levantamento feito pelo Laboratório de Políticas Públicas da UERJ (Universidade do Estado do Rio de Janeiro), publicado em janeiro de 2009, 51 instituições adotam ações afirmativas no Brasil, entre universidades estaduais e federais, faculdades, centros universitários e Cefets (GÓIS, 2009). Dentre as 35 universidades estaduais, 18 já adotam cotas, representando mais de 50\% do total. Das 53 universidades federais, 22 têm ações afirmativas (42\%), seja por meio de cotas ou de bonificação no vestibular, vantagens a alunos negros, pobres, de escola pública, deficientes ou indígenas. Contudo, as 
cotas são o sistema mais comum, com apenas sete instituições públicas adotando sistemas de bonificação (i.e. o candidato recebe pontos adicionais em relação aos demais, sem percentual de vagas preestabelecidas).

A Universidade Federal da Bahia instituiu um Programa de Ações Afirmativas no ano de 2004, estabelecendo reserva de vagas baseadas em critérios sociais e raciais. A partir de janeiro de 2005, 45\% das vagas passaram a ser restritas para candidatos egressos de escolas públicas. Dentre as vagas destinadas àqueles que cursaram o ensino médio no ensino público, $81,2 \%$ das vagas são destinadas àqueles que se declararam pretos ou pardos no ato da inscrição para o exame vestibular; $14,3 \%$ de qualquer etnia ou cor e $4,4 \%$ de indiodescendentes.

\section{REPRESENTAÇÕES SOCIAIS E POLÍTICA DE COTAS NAS UNIVERSIDADES}

Para Moscovici (1978), não existe uma representação sem objeto, pois a mesma é construída na relação do sujeito com o objeto representado. Dois processos são imprescindíveis na elaboração de uma representação, a dizer: objetivação e ancoragem - responsáveis pela interpretação e atribuição de significados ao objeto social (nesta pesquisa a política de cotas nas universidades). A objetivação é o processo que transforma a crença ou a opinião em informação (o abstrato em familiar), possibilitando a materialidade dos elementos, agora vistos como expressões da realidade natural. A ancoragem é o processo em que se dá a escolha de um quadro de referência (domínio familiar) para apreensão do objeto em estudo.

A implantação da Política de Cotas nas Universidades suscita discussões nos diversos segmentos da sociedade, nas pautas políticas, jurídicas e ideológicas por se tratar de um tema polêmico e no âmbito e contexto da universidade pública, no meio acadêmico, este debate e discussões têm sido mais evidentes, com posicionamentos de intelectuais e pesquisadores contrários (FRY; MAGGIE, 2004; GLÓRIA, 2006; LEITE, 2008; LEITE, 2011; LEWGOY, 2005; MAGGIE; FRY, 2002, 2004; MENIN et al., 2008; NEVES; LIMA, 2007; SANTOS, 2003) e favoráveis (ver GUIMARÃES, 1999, 2002; CARVALHO, 2003) a sua implantação.

De acordo com Guimarães (1999), a discussão sobre as políticas de ações afirmativas, seja nos Estados Unidos, seja no Brasil, engaja-se num debate em torno de duas perspectivas: na primeira delas, de ordem "axiológica e normativa", a discussão se estabelece em torno da correção ou não do tratamento diferenciado do individuo por suas características adscritas e grupais. A tese central dessa primeira perspectiva prioriza o mérito individual, ignorando a pertença social/grupal. A segunda perspectiva, de natureza "histórica e sociológica", prioriza, por meio da compreensão dos antecedentes sociais e históricos, verificar que impactos e possibilidades de construção tiveram ou podem vir a ter, sobre a estrutura social, a implantação de políticas de ações afirmativas de cunho e de intenção antidiscriminatórios em países plurirraciais ou étnicos, de credo democrático (GUIMARÃES, 1999). 
No debate acerca das ações afirmativas, em contraposição à perspectiva ideal-típica de meritocracia, os defensores das ações afirmativas se concentram na crítica ao mérito como ideologia. Isso implica assumir que por trás da defesa do mérito individual se esconderia, de fato, uma prática discriminatória. Justificam-se as ações afirmativas com a suposição de que, de fato, não existe nenhuma esfera social que opere com base no puro mérito. Como exemplo, têm-se as universidades norte-americanas que utilizam, na admissão de alunos, outros critérios - serem filhos de benfeitores ou membros do alummi; serem residentes regionais; terem habilidades esportivas, etc.

Dessa forma, ressalta-se a importância de conhecer e compreender as representações sociais de estudantes universitários acerca das políticas de cotas nas universidades, uma vez que estas influenciam a forma como estudantes que ingressaram na universidade com base em critérios distintos irão se relacionar no dia-a-dia da vida acadêmica. Espera-se que o conhecimento destas representações sociais possa auxiliar no planejamento de futuras intervenções com intuito de contribuir para a promoção das relações amigáveis e respeitosas entre os estudantes universitários, reduzindo, assim, a ocorrência de preconceito e discriminação direcionados aos estudantes "cotistas", constatados em estudos realizados após a implantação das cotas (CARVALHO, 2005b; NAIFF, D.; NAIFF, L; SOUZA, 2009; NEVES; LIMA, 2007).

Desta forma, com a perspectiva de compreender como os estudantes universitários, inseridos no contexto da adoção da política de cotas na universidade, representam a política de cotas, utilizou-se a Teoria das Representações Sociais por se tratar de uma abordagem psicossocial que procura dialetizar as relações entre indivíduo e sociedade. Ela considera o sujeito social portador de um mundo interior, ao passo, que o sujeito individual encontra-se restrito ao mundo social (MOSCOVICI, 1990). Neste sentido, ao abordar o tema das cotas universitárias, o estudo das representações sociais possibilita compreender os posicionamentos favoráveis e desfavoráveis acerca do tema em questão, bem como estabelecer um nexo sobre a formação e funcionamento dos sistemas de referências utilizados para classificar, neste estudo, os "cotistas" e interpretar acontecimentos da realidade. Por fim, possibilita análise mais cuidadosa dos mecanismos que interferem nas relações entre estudantes universitários na implantação do sistema de cotas universitárias, seja por meio da inserção ou rechaço dirigido a estudantes beneficiados pelas cotas universitárias.

Neste aspecto, a Teoria da Representações Sociais, na qual os indivíduos são vistos como sujeitos pensantes diante dos vários acontecimentos cotidianos de interação social e que produzem e comunicam as representações e soluções para as mais variadas questões de seu dia a dia (SÁ, 1998). Concebidas "enquanto fenômeno psicossocial estão necessariamente radicadas no espaço público e nos processos através dos quais o ser humano desenvolve uma identidade, cria símbolos e se abre para a diversidade de um mundo de Outros" (JOVCHELOVITCH, 2003, p. 65). Rompe com a tradição individualista predominante na psicologia social, visto que nela: 
não é um indivíduo isolado que é tomado em consideração mas sim as respostas individuais enquanto manifestações de tendências do grupo de pertença ou de afiliação na qual os indivíduos participam (SPINK, 2003, p. 120).

Neste sentido, as representações sociais são provenientes de um processo de pensamento social, portanto, se estabelecem mediante conjunção entre o pensar e as práticas sociais concretas por parte de grupos de indivíduos, a depender da natureza da situação em que estão inseridas, resultando das interações entre um contexto social e um tipo específico de prática social (CAMPOS, 1998).

Portanto, pensa-se que os estudantes universitários, enquanto atores sociais, envolvidos na presente pesquisa falam do lugar que ocupam na teia social, inseridos em um contexto especifico e imersos em valores, crenças e ideologias partilhadas socialmente. Pensando-se que estes atores não falam de forma isolada, mas representam seus grupos de pertença, a técnica do grupo focal torna-se uma ferramenta importante pois pode reunir indivíduos sociais que ao interagirem livremente e expressarem posicionamentos a respeito da política de cotas nas universidades, fazem uso de conteúdos linguísticos partilhados no âmbito do seu referencial identitário, seu grupo.

Pois, segundo Veiga e Gondim (2001), o grupo focal como técnica, pode ser caracterizado como um recurso para compreender o processo de construção das percepções, atitudes e representações sociais de grupos humanos. A pesquisa em representações sociais por meio de Grupo Focal:

reside no fato de que ela de certo modo simula as conversações espontâneas pelas quais as representações são veiculadas na vida cotidiana. [...] ponderando certo grau de artificialidade, os grupos focais podem fazer emergir uma boa quantidade dos mesmos temas e argumentos que fariam parte de uma conversação sobre o assunto no ambiente natural (SÁ, 1998, p. 93).

Augoustinos, Tuffin e Every (2005) realizaram uma pesquisa na qual foram conduzidos dois grupos focais com estudantes universitários australianos não aborígenes, como principais resultados deste estudo, pode-se ressaltar que os programas de ação afirmativa para estudantes indígenas foram taxados como inerentemente problemáticos, por violarem o princípio meritocrático, ao salientar a pertença grupal. Nesse sentido, a oposição à ação afirmativa foi legitimada e racionalizada por intermédio da evocação de ideais abstratos de liberalismo-igualitarismo e argumentos autossuficientes, como "todos devem ser tratados de forma igual" e "o mérito é a coisa mais importante", para se opor a ação afirmativa sem a necessidade de apresentar maiores esclarecimentos. A fala dos participantes se mostrou contraditória e ambivalente, já que eles enfatizavam as dificuldades que os indígenas enfrentam na sociedade e tinham consciência das vantagens que gozavam, fazendo parte do grupo dominante, mas, em outros momentos, faziam forte oposição à ação afirmativa, opondo-se a programas que visam reduzir as 
iniquidades para os grupos minoritários. Em algumas ocasiões, reconheciam a dificuldade de vencer tais obstáculos individualmente, e, em outras, avaliavam que as desvantagens eram superáveis para aqueles que tivessem força, vontade e caráter. Segunda as autoras, essas falas apareciam em paralelo, um modo de manejar a identidade do falante como justa, agradável e livre de preconceito. Entretanto, é importante perceber que justificando as iniquidades existentes, a oposição à ação afirmativa tem "consequências" racistas, uma vez que protege e mantém o privilégio dos brancos e deixa a desvantagem dos grupos minoritários intacta (AUGOUSTINOS; TUFFIN; EVERY, 2005).

De acordo com Santos e Chaves (2007), as representações sociais mais abrangentes, que predominam no âmbito de uma sociedade, são aquelas que expressam uma visão de mundo em determinado momento histórico, provenientes das concepções das classes dominantes. Desta maneira, estas representações abarcam a dominação, a resistência, o conformismo, as contradições e os conflitos, numa conexão dialética com a realidade. É nesse sentido e partindo do entendimento de que, como foi afirmado por Minayo (2003, p. 110) "cada grupo social faz da visão abrangente uma representação particular, de acordo com a sua posição no conjunto da sociedade" é que nos propomos a investigar qual a representação social de estudantes universitários sobre o sistema de cotas na universidade.

\section{MÉTOdo}

Trata-se de um estudo descritivo de caráter exploratório. A técnica adotada para colher os dados foi o grupo focal, definido por Morgan (1996) como uma técnica de pesquisa que coleta dados por meio das interações grupais ao se discutir um tópico especial sugerido pelo pesquisador. Como técnica, ocupa uma posição intermediária entre a observação participante e as entrevistas em profundidade. Pode ser caracterizado também como um recurso adotado para "compreender o processo de construção das percepções, atitudes e representações sociais de grupos humanos" (GONDIM, 2002a, p. 151).

A discussão grupal foi escolhida em vez de entrevistas individuais para facilitar uma aproximação maior, ainda que não naturalística, do tipo de argumentos utilizados para sustentar posições contrárias ou favoráveis às cotas, em conversas ou debates comuns no ambiente acadêmico (AUGOUSTINOS; TUFFIN; EVERY, 2005). Além de possibilitar que, mesmo aqueles participantes que nunca refletiram sobre o assunto, possam concordar ou discordar do que foi posto pelos demais, podendo acrescentar novas informações que suscitem outros posicionamentos (GONDIM, 2002b). Dessa maneira, ainda de acordo com Gondim (2002b), os grupos focais contribuem para o processo de mudança de atitudes, já que ao interagirem os participantes ficam expostos à opinião dos demais, o que propicia reflexão e avaliação de suas próprias crenças e experiências pessoais. 


\section{Participantes}

Participaram da pesquisa sete estudantes universitários de diversos cursos da Universidade Federal da Bahia. Trata-se de um grupo heterogêneo, com cinco mulheres, que entraram na universidade pelo sistema tradicional, e dois homens que entraram a partir das cotas. A idade média foi de 32 anos, variando de 19 a 49 anos. No que se refere à cor de pele, foram três brancos, dois pardos e dois pretos. A partir do semestre letivo cursado à época da pesquisa, do $1^{\circ}$ ao $8^{\circ}$ semestre, em 2008, podemos depreender que todos os participantes tiveram contato direto com colegas cotistas e vivenciaram a mudança dos critérios de seleção ao prestar o exame vestibular.

\section{Procedimentos}

Os estudantes cursavam uma disciplina em comum e já haviam respondido à pesquisa de Silva (2008), sobre normas sociais, preconceito racial e cotas. Foi feito um convite, em sala de aula, para que alguns deles participassem de uma nova investigação para ajudar a elucidar algumas questões que haviam ficado em aberto. O grupo focal foi formado pelos sete primeiros voluntários, Paula Silva, como moderadora e Joelma da Silva, como observadora. De início, explanou-se o objetivo e as regras para a condução da discussão no grupo focal. Foi feita uma apresentação entre os membros do grupo e, então, colocada a questão: "O que vocês pensam sobre o sistema de cotas na universidade?". Encerrada a discussão, os participantes responderam a um pequeno questionário com dados socioeconômicos e assinaram o termo de consentimento livre e esclarecido. Vale destacar que durante a discussão grupal a pesquisadora não tinha conhecimento sobre a forma de entrada dos estudantes na universidade.

Os dados foram transcritos e avaliados com base na técnica de análise de conteúdo temática, não quantitativa (BARDIN, 2009; SMITH, 2000).

\section{Resultados}

Os dados foram agrupados em dois eixos temáticos, sendo o primeiro aquele no qual os participantes se referiam ao sistema de cotas, enquanto projeto ou política, estabelecendo uma concepção abrangente e o segundo compreendido enquanto um sistema posto em prática, vislumbrando efetivamente as representações sociais do sistema de cotas no contexto da UFBA.

\section{Representações sociais do sistema de cotas enquanto PROJETO de ação afirmativa: concepção abrangente}

Partindo de uma concepção mais abrangente, análise macrossocial dos aspectos concernentes à educação brasileira, ou seja, num nível ideal, os participantes formularam acepções acerca da política de ações afirmativas enquanto um projeto de lei. 
Sendo assim, ao se referirem à política de cotas, enquanto projeto ou proposta de ação afirmativa alguns estudantes se posicionam contra, a favor ou de forma ambivalente, ora percebendo benefícios na política de cotas, ora concebendo-a como prejudicial.

\section{Contra}

Ao se posicionarem contrários ao projeto da política de cotas, os estudantes estabelecem que este projeto não proporciona contribuições reais para os beneficiários, segundo argumentos a seguir:

\section{Falha na educacão básica}

Posicionando-se contrários ao projeto da política de cotas, os estudantes consideram que a dificuldade para entrada nas universidades públicas, mediante o vestibular, se dá devido à precariedade na educação básica. Desta forma o Estado deveria priorizar uma educação básica de qualidade, sendo portanto, desnecessária a adoção da política de cotas nas universidades uma vez que ao se ter educação de qualidade os alunos provenientes de escolas publicas poderiam competir de igual para igual com alunos provenientes de escolas particulares do ensino básico, no processo seletivo de entrada nas universidade federais.

\section{Prefiro que [...] governo invista em uma educação básica de qualidade para favorecer o acesso a todos …] há piora, interfere (Amélia, ${ }^{1} 29$ anos, parda, não cotista, $8^{\circ}$ semestre de Pedagogia).}

\section{Não resolve a exclusão social}

Ainda ao se posicionarem contrários às cotas, por outro lado, argumentam que o acesso "facilitado" às universidades públicas não resolve o problema da exclusão, seja porque existem outros programas que proporcionam entradas nas instituições particulares de ensino superior, por meio de bolsas de estudos, a exemplo do Programa Universidade Para Todos (PROUNI), seja porque consideram que estas ações são meramente assistencialistas e, portanto, são temporárias.

Exclusão hoje não envolve exatamente o fato de você estar na UFBA ou não. O governo já instituiu outro programa, que é o PROUNI, que através dele você se inscrevendo no ENEM, que aliás é de graça [...] pros alunos que estudaram na escola pública durante o ensino médio, não é isso? Pra o ENEM você tem lá uma pontuação, que não é lá grande pontuação que é exigida, que você pode imediatamente através do ENEM, entrar numa faculdade particular, que o governo te dá uma bolsa praticamente integral, se não integral. Então eu acho que esse processo de exclusão já foi bastante minimizado nos dias atuais, entendeu? É isso, é a questão da exclusão, não justifica a essa questão das cotas na UFBA (Letícia, Ciências Contábeis, não cotista, negra). 
As cotas são ações é... do governo são questões meramente assistenciais, são questões temporárias, também, e você não pode dizer que você vai resolver o problema (Letícia).

\subsection{A favor}

Já os estudantes que se posicionam a favor do projeto da política de cotas argumentam que este tipo de ação promove a igualdade, inclusão e acesso à educação superior, além de conceber como sendo, em alguns casos, a única forma de a pessoa mudar sua condição social.

\section{Promoção da igualdade de oportunidades a todos}

Para alguns estudantes a política de cotas é um tipo de ação que promove a igualdade de oportunidades, direito constitucional, possibilitando, desse modo, que muitos, atualmente estejam na universidade. Além de considerar que este tipo de projeto também possibilita que a universidade deixe de ser elitizada, promovendo inclusão e acesso à educação superior.

Essa oportunidade é válida porque se não tivessem instituído cotas, muita gente que é cotista não estaria na universidade hoje, né, e a faculdade cada dia mais ia ser elitizada, entendeu? Ia ser elitizada, e quem não tem oportunidade de pagar, vai ser excluído, né, do acesso à educação (Henrique, 22 anos, pardo, cotista, $7^{\circ}$ semestre de Ciências Naturais).

Que a gente vê que educação, é na constituição mesmo fala que educação é pra todos, que universidade é para todos então isso vai mudar estatisticamente os dados que nós vemos aí na mídia (Letícia).

\section{Oportunidade para quem vem de baixo mudar de vida}

Outro argumento favorável a política de cotas é concebê-la como a única oportunidade para as pessoas de baixa renda, principalmente os negros, mudarem as suas vidas, gerando uma perspectiva de futuro diferenciada da sua realidade cotidiana de contato com a marginalidade.

Porque o preto da periferia nunca teve oportunidade, ta entendendo? Nunca teve oportunidade de mudar um quadro de vida que você tem na sua casa, no cotidiano. Então se ele vê o problema e não vê a solução, o que é que vai acontecer? Ele vai pro caminho errado. Então, se ele tem uma oportunidade de estudo, né, uma oportunidade de modificar esse quadro, eu acho que é relevante ter oportunidade de [...] de pessoa que vem de baixo e consegue ter um sucesso de vida (Henrique). 


\subsection{Ambivalente}

Alguns estudantes apresentaram discursos ambivalentes quanto ao posicionamento sobre a política de cotas. A princípio concordando que uma parcela da população permanece excluída do ensino superior e, portanto, seria legítimo a implementação da política de cotas ou algo similar de caráter emergencial e temporário ("tapa buraco"). Todavia, é visto como paliativo, pois entendem que apesar da possibilidade de causar prejuízos ainda assim é melhor que não se ter nada.

alguma coisa tem que ser feita. "não, num é legal, num é assim que tem que ser feito" é necessário [...] algo rápido [...] (Cláudio, 27, pardo, cotista, $7^{\circ}$, Direito).

"Tapa buraco" [...] "pode até prejudicar, mas que alivia mesmo" (Cláudio).

Talvez, como a colega falou, ela não devesse existir, mas talvez melhor ela existir do que não tenha nada (Lucy, 37, parda, não cotista, $7^{\circ}$, Pedagogia).

Eu acho que, que, sei lá, eu concordo, eu sei que tem falhas no projeto, eu sei que precisa se investir na escola pública, eu sei de tudo isso, mas ficar tendo o que tem agora do que nada [...] eu não sei. (Júlia, 19 anos, branca, não cotista, $1^{\circ}$ semestre de Administração).

\section{Representações sociais do sistema de cotas na UFBA: o sistema posto em prática}

O segundo eixo temático tem como característica principal a mudança do foco argumentativo, deslocando-se de uma discussão mais abrangente sobre a ação afirmativa para uma discussão mais local. Se antes a discussão era situada no contexto macro da educação brasileira, agora os participantes apontam mudanças já sentidas no âmbito da UFBA, após a absorção de alunos egressos de escolas públicas com condições socioeconômicas precárias.

Evidenciaram-se dois aspectos principais na imagem dos participantes sobre o aluno cotista: ele é percebido de forma estereotipada como portador de uma série de dificuldades que não são compatíveis com a rotina universitária, bem como alguém que necessita de auxílio para superar tais dificuldades, como veremos em detalhes a seguir.

\section{Dificuldades pessoais}

Os cotistas são representados como detentores de dificuldades pessoais inerentes, que impedem o bom acompanhamento do curso. Tais dificuldades são vistas como difíceis de serem superadas, sobretudo pela crença socialmente compartilhada da inviabilidade de o aluno da UFBA conciliar trabalho e estudo. 
A gente tem alguns colegas que entraram pelo sistema de cotas, aí o que acontece? MUITO deficiente. Trabalhar e estudar, simplesmente, é complicado aqui na UFBA. Eu tenho a impressão que quem chegar, chega (Amélia, 29 anos, parda, não cotista, $8^{\circ}$ semestre de Pedagogia).

\section{Dificuldades financeiras}

Existe uma percepção de que os cotistas apresentam sérias dificuldades financeiras, não apenas individuais, para obter insumos indispensáveis na rotina acadêmica, como material didático, mas também familiares, não tendo acesso a necessidades básicas de subsistência.

E o pessoal não tem condição de tirar xerox. Os meninos não tem dinheiro pra tirar xerox! As meninas não têm dinheiro pra comer! A gente tem colegas que a gente sabe, que não tem comida em casa e não tem o que comer [...] (Amélia).

\section{Dificuldades cognitivas}

Os alunos cotistas são concebidos como menos preparados intelectualmente para acompanhar o curso que aqueles que entraram pelo sistema tradicional. Além disso, parece não haver um preparo por parte dos alunos e professores para lidar com este "desnível", percebido, decorrente de um déficit na formação básica dos egressos de escolas públicas.

Tem dificuldade de raciocínio, de raciocinar, isso atrapalha muito na sala, então, entra pelo sistema, mas não consegue, ahn, dar conta, já não dá conta de assuntos [...] Então causa um mal-estar enorme, com os colegas, com os professores [baixa o tom de voz], é uma situação muito estranha, muito estranha. Tem acesso, mas não consegue se manter (Amélia).

\section{Dificuldades psicológicas}

Houve também, devido ao quadro de tantas dificuldades, a associação dos cotistas a pessoas que vivenciam sofrimento psíquico elevado.

Então, tem ideias soltas, de pessoas que tá correndo desestabilizada mesmo, transtorno tem algumas que tem acompanhamento psiquiátrico (Amélia).

\section{Necessidade de apoio à permanência}

Foi considerado por todos de extrema importância concentrar as aulas em turnos, para que o aluno cotista possa se manter autonomamente na universidade.

Concentrar turnos, né, pra ter possibilidade da pessoa estudar num turno e trabalhar no outro... ele que vai ser 
responsável por si, certo, vai poder se manter dentro da própria universidade (Henrique, 22 anos, pardo, cotista, $7^{\circ}$ semestre de Ciências Naturais).

Além disso, foram apontadas necessidades de mudanças estruturais na UFBA para viabilizar a permanência dos cotistas, como residência universitária, transporte gratuito inter campus etc.

Eu já vi lá a construção de um restaurante novo, então deve estar dentro desse projeto essa melhoria pensando nessas pessoas carentes que estão entrando na universidade... É, e antes disso, uma bolsa, um jeito deles trabalharem também, até na própria universidade, né? Eu acho que poderia até, sim, prestar serviços na universidade, como auxiliar administrativo, operando na recepção, de trabalhar com turno, agendar. Eu acho que poderia ser uma campanha boa, uma solução inteligente, e que as pessoas possam também participar da vida social na universidade (Zulmira, 49 anos, branca, não cotista, $1^{\circ}$ semestre de Psicologia).

\section{$\underline{\text { Meritocracia X Igualdade }}$}

Há uma dupla representação do processo de inserção dos alunos beneficiados por cotas raciais e sociais. Por um lado as cotas são percebidas como injustas, por ferirem a norma da meritocracia, argumento que vem impregnado de um componente de ameaça de perda de benefícios adquiridos enquanto grupo dominante:

Assim, eu discordava das cotas, principalmente quando eu estudava em colégio (particular), tinha toda aquela trajetória do vestibular e, poxa, uma pessoa que, que passou no vestibular não conseguir entrar por causa de uma pessoa que tirou uma nota menor (Júlia, 19 anos, branca, não cotista, $1^{\circ}$ semestre de Administração).

Por outro lado, os membros do grupo dominante conseguem perceber que o grupo minoritário, por conta das desigualdades sociais e econômicas, está em situação de desvantagem que inviabiliza uma competição justa no vestibular:

Mas hoje eu concordo, eu acho que assim, se você não fizer isso, nada mais acontece, já não está se investindo nas escolas, na nas escolas públicas, nas crianças pequenas, mesmo que se investisse nas escolas públicas ia levar muito tempo, como você falou (Leila), ia levar muito tempo pra ele entrar na faculdade [...] (Júlia).

Nota-se, ao final desta mesma fala, a crença de que os alunos cotistas não estão no mesmo nível do que os demais estudantes:

[...] pra daí sim, eles conseguirem estudar de igual para igual (Júlia). 


\section{$\underline{\text { Melhoria de vida }}$}

Mesmo com todas as dificuldades de adaptação, as cotas na UFBA foram representadas pelos beneficiados como positivas, indicando uma possibilidade real de melhoria de vida a partir do acesso à educação superior pública e de qualidade.

Nós passamos aqui quase um período de nossas vidas, que são [sic] muito, são [sic] muito tempo. Então nós sabemos o que nós passamos na pele. Então quando as pessoas entram aqui na universidade, os estudantes calouros têm que se esforçar pra se adequar ao ensino na universidade, pra gente se habituar, é (um esforço) muito grande. Eu me lembro, eu tiro por mim. Então a gente vem aqui entender como é o sistema, estudar, e tentar se manter e se desenvolver, e sair daqui com a cabeça bem melhor do que nós entramos, porque nós saímos daqui totalmente transformados - para melhor, com toda certeza (Henrique, 22 anos, pardo, cotista, $7^{\circ}$ semestre de Ciências Naturais).

\section{DisCUSSÃo}

No grupo focal, as representações sociais dos estudantes sobre a política de cotas na universidade mostraram-se contraditórias e ambivalentes.

Os estudantes argumentaram ser contrários às cotas por avaliarem que elas ferem o princípio meritocrático, sendo uma medida meramente assistencialista, por permitir acesso a estudantes que julgam não apresentar condições intelectuais e econômicas mínimas para, de fato, manterem-se nos cursos. No entanto, os participantes tentaram se mostrar favoráveis à adoção da medida, mas, justificavam esta postura pelo descrédito na intervenção do governo para a melhoria da educação fundamental, o que facilitaria o acesso a todos os grupos sociais. Ou seja, com base neste argumento, as cotas só seriam avaliadas como medida justa e promotora da igualdade social entre grupos se as mesmas não existissem. Outro aspecto também curioso, foi o fato de que os estudantes apresentaram um discurso ambivalente por considerarem a legitimidade de ações que visam resolver o problema da exclusão no acesso ao ensino superior, mas que por outro lado, a política de cotas não seria o melhor caminho. Contudo, acrescentaram que na falta de outros projetos e ações esta seria a melhor alternativa. Houve, ainda, relatos de dificuldades econômicas, emocionais e cognitivas de alguns colegas cotistas em acompanhar o curso, produzindo o que denominaram de situações desconfortáveis em sala de aula.

Percebemos um claro processo de estereotipização dos alunos cotistas, que são representados enquanto grupo homogêneo e diverso dos demais estudantes. Este processo se evidencia quando dificuldades que sempre foram tidas como inerentes à UFBA - como a questão de conciliar trabalho e estudos, por conta da falta de concentração das aulas em um único turno, passa a ser ressaltada e exaltada como algo incontornável quando se trata de alunos cotistas. Contudo, ao 
apresentar essa inviabilidade, a própria participante indicou que, no grupo, havia participantes que cursavam duas faculdades e outro que dava aulas à noite, neste caso, Henrique, um dos beneficiados pelo sistema de cotas.

Ademais, com base nos dados de Silva (2008), fica claro que os cotistas estão longe de ser um grupo homogêneo, sobretudo no que se refere ao aspecto socioeconômico, já que alunos egressos dos CEFET e do Colégio Militar, que muitas vezes possuem uma condição financeira familiar confortável, podem se inscrever para disputar vagas por cotas, por serem egressos de escola pública. Como foi informado por Cláudio: "Tem alunos que nem são cotistas, mas são pobres. E um fato muito curioso é que tem alunos que não são pobres, nem nunca foram, mas são cotistas."

Este estudo tem caráter exploratório e, sem dúvida, apresenta algumas limitações, sobretudo em termos de abrangência e profundidade. Os participantes do grupo focal haviam respondido à outra pesquisa da autora, que teve acesso, por meio de estratégias diretas e indiretas, ao preconceito racial e às atitudes dos participantes em relação às cotas, analisando o papel das normas sociais da meritocracia e da igualdade na manifestação de respostas preconceituosas. Decerto, este contato prévio pode ter deixado os participantes ainda mais alertas e receosos ao tratar do tema, tendo em vista que o caráter racial das cotas ficou latente e foi evitada sua manifestação direta na discussão.

\section{Nota}

${ }^{1}$ Para preservar o anonimato dos participantes, os nomes aqui apresentados são fictícios.

\section{REFERÊNCIAS}

AUGOUSTINOS, M., TUFFIN, K.; EVERY, D. New racism, meritocracy and individualism: constraining affirmative action in education. Discourse \& Society, London, v. 16, n. 3, p. 315-340, 2005.

BARDIN, L. Análise de Conteúdo. Lisboa: Edições 70, 2009.

BRANDÃO, C. F. As cotas na universidade pública brasileira: será esse o caminho? Campinas, SP: Autores Associados, 2005. Coleção polêmicas do nosso tempo, 92 .

CAMPOS, P. H. F. As representações sociais de "meninos de rua": proximidade do objeto e diferenças estruturais. In: MOREIRA, A. S. P.; OLIVEIRA, D. C. (Org.). Estudos interdisciplinares de representação social. Goiânia: AB, 1998. p. 271-283.

CARVALHO, J. J. As ações afirmativas como resposta ao racismo acadêmico e seu impacto nas ciências sociais brasileiras. Teoria \& Pesquisa: Revista de Ciência Política, São Paulo, v. 1, n. 42 e 43, p. 303-340, jan./jul. 2003. 
CARVALHO, J. J. Usos e abusos da antropologia em um contexto de tensão racial: o caso das cotas para negros na UNB. Horizontes Antropológicos, v. 11, n. 23 , p. 237-246, 2005a.

CARVALHO, J. J. Inclusão étnica e racial no Brasil: a questão das cotas no ensino superior. 1. ed. São Paulo: Attar, 2005b.

CROSBY, F. J.; CORDOVA, D. I. Words worth of widsdom: toward an understanding of affirmative action. Journal of Social Issues, [S.1.], v. 52, n. 4, p. 33-49, 1996.

FRY, P.; MAGGIE, Y. Cotas raciais: construindo um país dividido? Econômica, Rio de Janeiro, v. 6, n. 1, p. 153-161, jun. 2004.

GLÓRIA, M. C. S. Políticas de ação afirmativa para negros: novas propostas para antigos problemas. Dissertação (Mestrado em Serviço Social)-Programa de Pós-Graduação em Serviço Social, Universidade Federal do Rio de Janeiro, Rio de Janeiro, 2006.

GOIS, A. 51\% das universidades estaduais adotam ações afirmativas. Folha de S. Paulo, São Paulo, 08 jan. 2008. Disponível em: <http://www.direitos.org.br/ index.php?option $=$ com_content $\&$ task $=$ view $\&$ id $=4442 \& I t e m i d=2>$. Acesso em: 02 fev. 2009.

GOMES, J. B. B.; SILVA, F. B. B. As ações afirmativas de promoção da igualdade efetiva. Cadernos do Conselho da Justiça Federal, Brasília, p. 85-124, 2003: Disponível em: www.cjf.gov.br/revista/seriecadernos/vol24/artigo04.pdf . Acesso em: 03 nov. 2007.

GOMES, J. B. B. O debate constitucional sobre as ações afirmativas. In: SANTOS, R. E.; LOBATO, F. (Org.). Ações afirmativas: políticas públicas contra as desigualdades raciais. Rio de Janeiro: DP\&A, 2003. p.15-58.

GONDIM, S. M. G. Grupos focais como técnica de investigação qualitativa: desafios metodológicos. Paidéia, Ribeirão Preto, v. 12, n. 24, p. 149-161, 2002a.

GONDIM, S. M. G. Perfil profissional e mercado de trabalho: relação com formação acadêmica pela perspectiva de estudantes universitários. Estudos de Psicologia, Natal, v. 7, n. 2, p. 299-309, jul./dez. 2002 b.

GUIMARÃES, A. S. Racismo e anti-racismo no Brasil. São Paulo, Editora 34, 1999.

GUIMARÃES, A. S. Classe, Raça e Democracia. São Paulo: Ed. 34, 2002. 
HING, L. S. S; BOBOCEL, D. R.; ZANNA, M. P. Meritocracy and opposition to affirmative action: making concession face the discrimination. Journal of Personalite and Social Psychology, [S.1.], v. 83, n. 3, p. 493-509, 2002.

JONES, J. E. The rise and fall of affirmative action. In: HILL, H; JONES, J. (Ed.). Race in American: the struggle for equality. Madison: University of Wisconsin, 1993. p. 345-369.

JOVCHELOVITCH, S. Vivendo a vida com os outros: intersubjetividade, espaço público e representações sociais. 10. ed. In: GUARESCHI, P. A.; JOVCHELOVITCH, S. (Org.). Textos em representações sociais. Petrópolis: Vozes, 2003. p.63-85.

LEITE, J. L. Política de assistência estudantil: entre o direito e o favor. Universidade e Sociedade, Brasília, ano XVII, n. 41, p. 165-173, jan. 2008.

LEITE, J. L. Política de cotas no Brasil: política social? Rev. Katálysis, Florianópolis, v. 14, n. 1, p. 23-31, 2011. Disponível em: <http://www.scielo.br/ pdf/rk/v14n1/v14n1a03.pdf>. Acesso em: 25 jul. 2012.

LEWGOY, B. Cotas raciais na UnB: as lições de um equívoco. Horizonte antropológico, Porto Alegre, v. 11, n. 23, p. 218-221, jun. 2005. Disponível em: <http://www.scielo.br/pdf/ha/v11n23/a13v1123.pdf>. Acesso em: 06 nov. 2012.

MAGGIE, Y.; FRY, P. O debate que não houve: a reserva de vagas para negros nas universidades brasileiras. Enfoques, Rio de Janeiro, v. 1, n.1, p. 93-117, 2002.

MAGGIE, Y.; FRY, P. A reserva de vagas para negros nas universidades brasileiras. Estudos Avançados, v. 18, n. 50, p. 67-80, jan./abr. 2004.

MENIN, M. S. S. et al. Representações de estudantes universitários sobre alunos cotistas: Confronto de valores. Educação e Pesquisa, São Paulo, v. 34, n. 2, p. 255-272, 2008.

MINAYO, M. C. S. O conceito de representações sociais dentro da sociologia clássica. 10. ed. In: GUARESCHI, P. A.; JOVCHELOVITCH, S. (Org.). Textos em representações sociais. Petrópolis: Vozes, 2003. p. 89-111.

MOEHLECKE, S. Ação afirmativa: história e debates no Brasil. Cadernos de Pesquisa, São Paulo, n. 117, p. 197-217, nov. 2002.

MORGAN, D. L. Focus Groups. Annu. Rev. Sociol., v. 22, p. 129-152, 1996.

MOSCOVICI, S. A representação social da psicanálise. Rio de Janeiro: J. Zahar. 1978. 
MOSCOVICI, S. (Org.). Introduction: le domaine de la psychologie sociale. In: . Psychologie sociale. 2. ed. Paris: Presses Universitaires de France, 1990. $\overline{\text { p. } 05-24 .}$

NAIFF, D. G. M.; NAIFF, L. A. M.; SOUZA, M. A. As representações sociais de estudantes universitários a respeito das cotas para negros e pardos nas universidades públicas brasileiras. Estudos e Pesquisas em Psicologia, Rio de Janeiro, v. 9, n. 1, p. 216-229, 2009.

NEVES, P. S. C.; LIMA, M. E. O. Percepções de justiça social e atitudes de estudantes pré-vestibulandos e universitários sobre as cotas para negros e pardos nas universidades públicas. Revista Brasileira de Educação, Rio de Janeiro, v. 12, n. 34, p. 17-38, 2007.

SÁ, C. P. de. A construção do objeto de pesquisa em Representações Sociais. Rio de Janeiro: EdUERJ, 1998.

SANTOS, G. L.; CHAVES, A. M. Ser quilombola: representações sociais de habitantes de uma comunidade negra. Estudos de Psicologia, Campinas, v. 24, n. 3, p. 353-361, jul./set. 2007.

SANTOS, S. A. Ação afirmativa e mérito individual. In: SANTOS, R. E.; LOBATO, F. (Org.), Ações afirmativas: políticas públicas contra as desigualdades raciais. Rio de Janeiro: DP\&A, 2003. p. 83-126.

SILVA, P. B. Normas Sociais e Preconceito: o impacto da meritocracia e da igualdade no preconceito implícito e explícito contra os cotistas. 2008. Dissertação (Mestrado)-Universidade Federal da Bahia, Salvador, 2008.

SMITH, C. P. Content analysis and narrative analysis. In: REIS, H. T.; JUDD, C. M. (Org.). Handbollk of Research Methods in social and personality psychology. Cambridge: Cambridge University, 2000. p. 313-335.

SOWELL, T. Ação afirmativa ao redor do mundo: estudo empírico. Rio de Janeiro: UniverCidade, 2004.

SPINK, M. J. Desvendando as teorias implícitas: uma metodologia de análise das representações sociais. 10. ed. In: GUARESCHI, P. A.; JOVCHELOVITCH, S. (Org.). Textos em representações sociais. Petrópolis: Vozes, 2003. p. 117-145.

VEIGA, L.; GONDIM, S. M. G. A utilização de métodos qualitativos na ciência política e no marketing político. Opinião Pública. Campinas, v. 7, n. 1, p. 1-15, 2001.

Recebido em: 14 de julho de 2010

Aceito em: 13 de agosto de 2012 